\title{
Visinin-Like Neuronal Calcium Sensor Proteins Regulate the Slow Calcium-Activated Afterhyperpolarizing Current in the Rat Cerebral Cortex
}

\author{
Claudio Villalobos and Rodrigo Andrade \\ Department of Pharmacology, Wayne State University School of Medicine, Detroit Michigan 48230
}

\begin{abstract}
Many neurons in the nervous systems express afterhyperpolarizations that are mediated by a slow calcium-activated potassium current. This current shapes neuronal firing and is inhibited by neuromodulators, suggesting an important role in the regulation of neuronal function. Surprisingly, very little is currently known about the molecular basis for this current or how it is gated by calcium. Recently, the neuronal calcium sensor protein hippocalcin was identified as a calcium sensor for the slow afterhyperpolarizing current in the hippocampus. However, while hippocalcin is very strongly expressed in the hippocampus, this protein shows a relatively restricted distribution in the brain. Furthermore, the genetic deletion of this protein only partly reduces the slow hyperpolarizing current in hippocampus. These considerations question whether hippocalcin can be the sole calcium sensor for the slow afterhyperpolarizing current. Here we use loss of function and overexpression strategies to show that hippocalcin functions as a calcium sensor for the slow afterhyperpolarizing current in the cerebral cortex, an area where hippocalcin is expressed at much lower levels than in hippocampus. In addition we show that neurocalcin $\delta$, but not VILIP-2, can also act as a calcium sensor for the slow afterhyperpolarizing current. Finally we show that hippocalcin and neurocalcin $\delta$ both increase the calcium sensitivity of the afterhyperpolarizing current but do not alter its sensitivity to inhibition by carbachol acting through the $\mathrm{G} \alpha_{\mathrm{q}-11}-\mathrm{PLC} \beta$ signaling cascade. These results point to a general role for a subgroup of visinin-like neuronal calcium sensor proteins in the activation of the slow calcium-activated afterhyperpolarizing current.
\end{abstract}

\section{Introduction}

Repetitive spiking by pyramidal cells of the hippocampus and cortex results in the development of a slow afterhyperpolarization (sAHP) that controls spike frequency accommodation (Madison and Nicoll, 1984; Schwindt et al., 1988b) and regulates neuronal gain (Higgs et al., 2006). Similar slow hyperpolarizing afterpotentials have also been reported in many other cell types, suggesting that sAHPs are ubiquitous regulators of neuronal excitability (Faber and Sah, 2003; Vogalis et al., 2003). A general property of these sAHPs is that they are regulated by neuromodulators signaling via $\mathrm{G} \alpha_{\mathrm{q}-11}$ or through the $\mathrm{G} \alpha_{\mathrm{s}}$ /adenylate cyclase/ cAMP/protein kinase A signaling cascade (Madison and Nicoll, 1982; Schwindt et al., 1988a; Pedarzani and Storm, 1993; Krause et al., 2002). Thus the sAHP is an important determinant of cellular excitability in a variety of cell types in the CNS and an important target for many neuromodulators.

There is now widespread consensus that the sAHP is mediated by a calcium-activated potassium current generally referred to as $I_{\text {SAHP }}$ (Faber and Sah, 2003; Vogalis et al., 2003). Surprisingly, however, neither the ion channel(s) carrying $I_{\mathrm{sAHP}}$ nor the mechanism through which this current is gated by calcium are well

Received July 2, 2010; revised Aug. 27, 2010; accepted Sept. 3, 2010.

This work was supported by National Institutes of Health Grant MH43985. We thank Elaine Weber for technical assistance.

Correspondence should be addressed to Rodrigo Andrade, Department of Pharmacology, 3108 Scott Hall, Wayne State University School of Medicine, 540 East Canfield Street, Detroit, MI 48230. E-mail: randrade@med.wayne.edu. DOI:10.1523/JNEUROSCI.3440-10.2010

Copyright $\odot 2010$ the authors $\quad 0270-6474 / 10 / 3014361-05 \$ 15.00 / 0$ understood. A recent breakthrough occurred with the discovery that the genetic deletion of the neuronal calcium sensor (NCS) hippocalcin results in the inhibition of $I_{\mathrm{sAHP}}$ in hippocampal pyramidal cells. This observation has led to the idea that hippocalcin is the calcium sensor for $I_{\mathrm{sAHP}}$ (Tzingounis et al., 2007). However, while $I_{\text {SAHP }}$ is a broadly expressed cellular property in many regions of the brain, the expression of hippocalcin is much more restricted (Saitoh et al., 1994; Paterlini et al., 2000). Furthermore, hippocalcin deletion inhibits but does not abolish $I_{\mathrm{sAHP}}$ in hippocampal pyramidal cells. These considerations suggest that hippocalcin may not be the only NCS protein capable of functioning as a calcium sensor for $I_{\text {SAHP. }}$. The cerebral cortex offers the opportunity to address this issue since hippocalcin is expressed in this area at levels considerably lower than in hippocampus (Saitoh et al., 1994), but cortical pyramidal cells display a robust and well characterized $I_{\mathrm{sAHP}}$. In the present work, we have taken advantage of these properties to readdress the role of hippocalcin in the regulation of $I_{\mathrm{SAHP}}$.

\section{Materials and Methods}

Experiments were conducted on cortical brain slices either acutely prepared or maintained in organotypic culture (Villalobos et al., 2004; Yan et al., 2009). Briefly, rats or mice during the second (organotypic) or third to fifth (acute) postnatal weeks were anesthetized with halothane or isoflurane and killed by decapitation. The brain was removed and cooled in ice-cold Ringer's solution of standard composition (in mM: $119 \mathrm{NaCl}$, $2.5 \mathrm{KCl}, 1.3 \mathrm{MgSO}_{4}, 2.5 \mathrm{CaCl}_{2}, 1 \mathrm{NaH}_{2} \mathrm{PO}_{4}, 26.2 \mathrm{NaHCO}_{3}$, and 11 glucose), supplemented with 10 mM HEPES and bubbled to saturation with $95 \% \mathrm{O}_{2}, 5 \% \mathrm{CO}_{2}$. The brain was blocked and coronal brain slices of a 
nominal thickness of $300 \mu \mathrm{m}$ were cut using a vibratome. For organotypic culture, slices were collected in sterile Ringer's solution and placed in culture essentially as described by Stoppini et al. (1991).

Electrophysiological recordings were obtained from pyramidal cells of layer II-III (shRNA experiment) or layer V (NCS expression experiments) of the medial prefrontal/anterior cingulate cortices as previously described (Villalobos et al., 2004, 2005; Yan et al., 2009). Slices were transferred one at a time to a recording chamber on the stage of a Nikon E600 microscope, where they were held in place by a platinum and nylon grid. Slices in the recording chamber were perfused continuously with Ringer's solution at $30 \pm 1{ }^{\circ} \mathrm{C}$ bubbled to saturation with $95 \% \mathrm{O}_{2}$ and $5 \%$ $\mathrm{CO}_{2}$. Whole-cell recordings were obtained using a potassium-based intracellular solution (composition in mM: $\mathrm{KMeSO}_{4} 120, \mathrm{KCl} 5, \mathrm{NaCl} 5$, EGTA 0.02, HEPES $10, \mathrm{MgCl}_{2} 1$, Na phosphocreatine 10, ATP magnesium salt 4, GTP Na salt 0.3, myo-inositol 30). Electrodes filled with this solution exhibited resistances ranging from 2 to $4 \mathrm{M} \Omega$. Because holding currents and $I_{\mathrm{sAHP}}$ amplitudes were relatively small, series resistance was left uncompensated. All recording were conducted using a Multiclamp amplifier under the control of pClamp 9 (Molecular Devices).

Pyramidal neurons were transfected using either in utero electroporation (shRNA experiments) or particle mediate gene transfer (NCS expression experiments). In utero electroporation was conducted on embryonic mice at E14.5 as described by Saito (2006) and used a pool of five shRNAs targeting hippocalcin to maximize the suppression of hippocalcin expression (Parsons et al., 2009). These shRNAs were developed by the RNAi Consortium, and their expression was driven by the U6 promoter in the pLKO.1-puro vector (Mission RNAi, Sigma) (supplemental Fig. S1, available at www.jneurosci.org as supplemental material). YFP in pCAG (Addgene) at a 4:1 ratio was electroporated with the shRNA to serve as a transfection marker. Particle-mediated gene transfer was conducted as previously described (Villalobos et al., 2004; Yan et al., 2009). Gold particles were coated with plasmids encoding either hippocalcin (in pCMV-Sport6, ATCC Cat. No. 10470251/MGC Image ID 5360894), neurocalcin $\delta$ (in pCMV-Sport6, ATCC Cat. No. MGC-36496/ MGC Image ID 5365560), or VILIP-2 (in pcDNA3.1, a kind gift from Dr. W. A. Catterall, University of Washington, Seattle, WA) (Lautermilch et al., 2005) and EGFP (pEGFP-N1, Clontech) at a 4:1 ratio. In all these vectors, expression was driven by the CMV promoter, which effectively drives gene expression in this preparation (Béique and Andrade, 2003). The PLC $\beta 1$ knock-out mouse (Kim et al., 1997) was a kind gift from Drs. R. K. Wong (SUNY Downstate Medical Center, Brooklyn, NY) and H. S. Shin (Korea Institute of Science and Technology, Seoul, Korea).

For experiments examining the effect of the shRNA targeting hippocalcin, we used cells in the untransfected side of the brain as controls, rather than non-YFP-expressing cells in the transfected side, because preliminary experiments indicated that detectable YFP expression in a cell in vivo did not unambiguously identify untransfected neurons in the transfected side (supplemental Fig. S2, available at www.jneurosci.org as supplemental material). Experiments aimed at examining the effects of expressing NCS proteins used paired recordings from neighboring layer $\mathrm{V}$ transfected and untransfected pyramidal neurons located within $\sim 150$ $\mu \mathrm{m}$ of each other. This approach was preferred to using mock transfections in separate slices for the controls because it allows for a more stringent cell match with respect to cell location and slice history. We have previously shown that transfection with EGFP has no detectable effect on $I_{\mathrm{sAHP}}$ (Yan et al., 2009) and the very low transfection efficiency of the gene gun assured that the overwhelming fraction of non-GFPexpressing cells correspond to untransfected neurons. All organotypic slice recordings were obtained 2-3 d after transfection.

Pyramidal cells were held at $-60 \mathrm{mV}$ and $I_{\mathrm{sAHP}}$ was triggered using a 100 -ms-long depolarizing step in voltage clamp. In most experiments, we administered apamin $(300 \mathrm{~nm})$ to block $I_{\mathrm{mAHP}}$. This allowed us to estimate the amplitude of $I_{\mathrm{mAHP}}$ for most cells and also to record $I_{\mathrm{sAHP}}$ in isolation. $I_{\mathrm{sAHP}}$ amplitude was determined $\sim 300 \mathrm{~ms}$ after the end of the triggering step. The voltages reported are not corrected for the liquid junction potential. Most drugs were obtained from Sigma or Fisher. Tetrodotoxin was obtained from EMD Biosciences, while apamin was obtained from Tocris Bioscience. All drugs were administered to the slice dissolved in the bath. Statistical comparisons used $t$ tests.
$A_{1}$

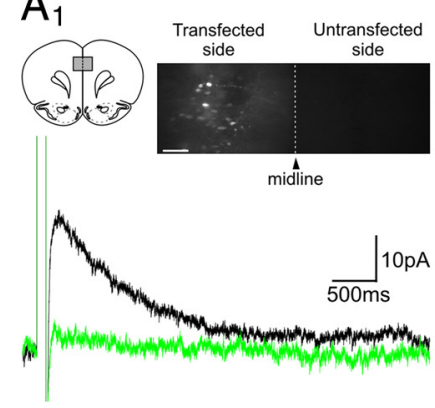

$\mathrm{B}_{1}$
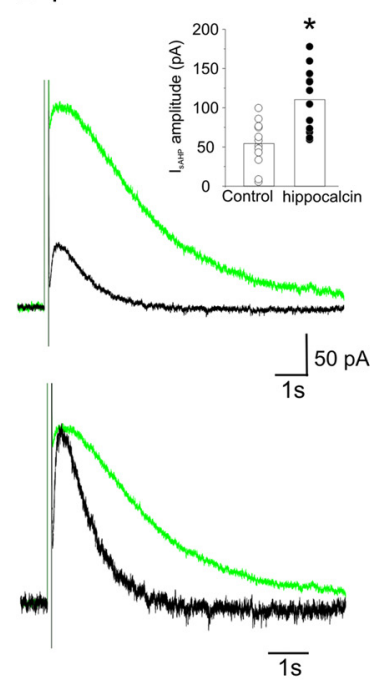

$\mathrm{A}_{2}$

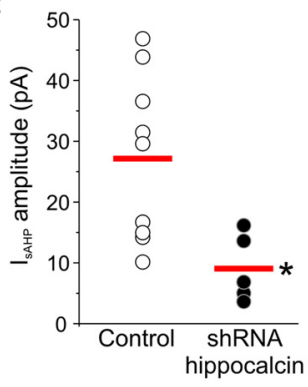

$\mathrm{B}_{2}$
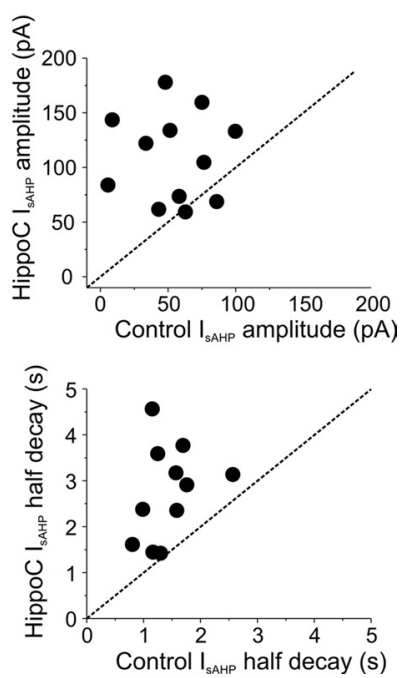

Figure 1. Hippocalcin expression regulates $I_{\text {sAHP. }} A_{1}$, Superimposed traces illustrating $I_{\text {SAHP }}$ recorded from shRNA/YFP-transfected (green) and untransfected (black) pyramidal cells. Inset, Fluorescence image depicting transfected and untransfected cingulate cortices in a living brain slice at the approximate position illustrated in the diagram. Calibration bar $=100 \mu \mathrm{m} . A_{2}$, Graph summarizing the amplitude of $I_{\text {sAHP }}$ in 5 shRNA/YFP-transfected and 9 control untransfected cells. ${ }^{*} p<0.05$. $\boldsymbol{B}_{\boldsymbol{1}}$, Superimposed traces depicting $I_{\text {sAHP }}$ recorded in a pair of hippocalcin-transfected (green) and neighboring untransfected (black) pyramidal cells in organotypic slices. Lower panel illustrates the same slices scaled to emphasize the change in the time course of $I_{\text {sAHP. }}$. Inset, Effect of hippocalcin on the amplitude of $I_{\text {sAHP. }}{ }^{*} p<0.001$. $B_{2}$, Graphs illustrating the effects of hippocalcin expression on the amplitude (upper plot) and decay (lower plot) of $I_{\text {sAHP }}$ for each cell pair tested in this experiment. The half decay for only 11 cell pairs is depicted in the lower graph because it was not possible to estimate the half decay for $I_{\text {sAHP }}$ in one of the control cells.

\section{Results}

In a first experiment, we used in utero electroporation to express shRNAs targeting hippocalcin in layer II-III pyramidal cells of cingulate cortex to ask whether hippocalcin played a role regulating $I_{\mathrm{sAHP}}$ in this area. Previous studies have shown the effectiveness of this shRNA approach to knockdown the expression of specific proteins (e.g., Bai et al., 2003; Parsons et al., 2009), and we confirmed the effectiveness of this strategy in the current experiments using immunohistochemistry to confirm the knockdown of hippocalcin expression in transfected cortical neurons of the upper layers of cortex (supplemental Fig. S3, available at www. jneurosci.org as supplemental material). As illustrated in Figure $1 A$, transfection of shRNAs targeting hippocalcin resulted in a significant reduction in the amplitude of $I_{\text {sAHP }}$ in YFP-expressing pyramidal cells when compared to the amplitude of $I_{\text {sAHP }}$ in pyramidal cells matched for location on the (nontransfected) contralateral cortex. 

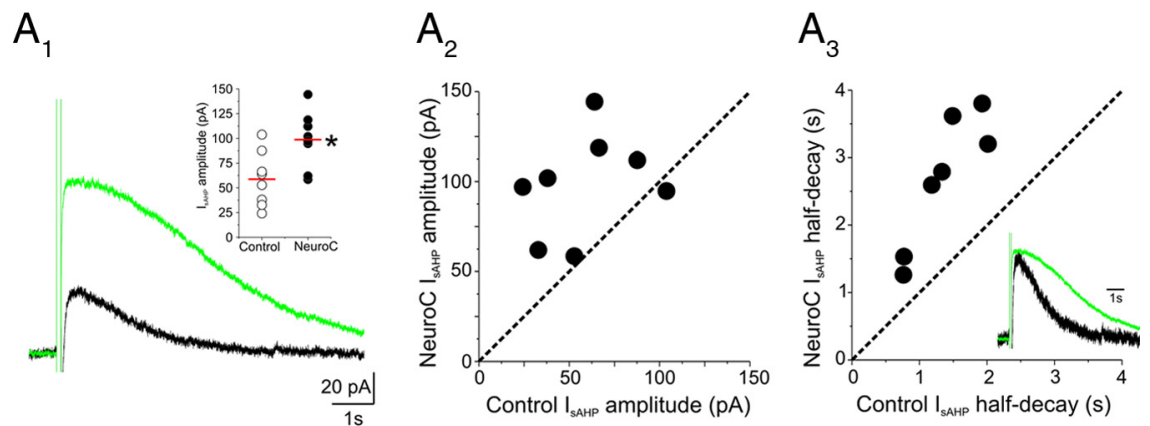

$\mathrm{B}_{1}$

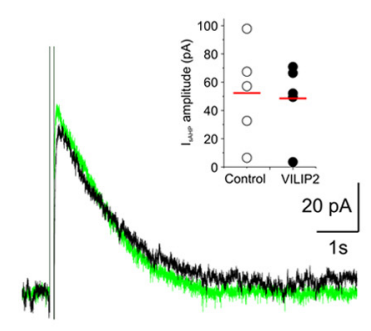

$\mathrm{B}_{2}$

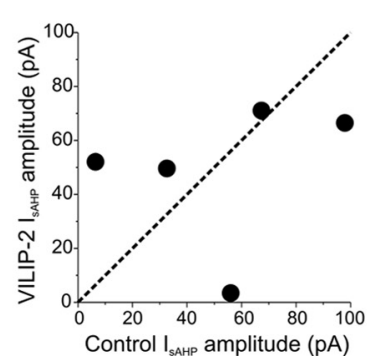

$\mathrm{B}_{3}$

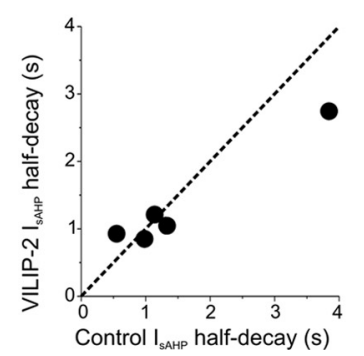

fected and untransfected pyramidal cells (Béique et al., 2007; Yan et al., 2009). As illustrated in Figure $1 B$, expression of hippocalcin resulted in a large increase in the amplitude of $I_{\mathrm{sAHP}}$ (from $54 \pm 8$ to $110 \pm$ $12 \mathrm{pA}, n=12$ cell pairs, $p<0.01)$ that was accompanied by a significant slowing of its decay kinetics $(p<0.01)$. Since expression of hippocalcin had no significant effect on cell resting membrane potential, input resistance, or the amplitude of the apamin-sensitive calcium-activated potassium current $I_{\mathrm{mAHP}}$ (supplemental Table S1, available at www.jneurosci. org as supplemental material), we interpret these loss of function and overexpression experiments to indicate that hippocalcin regulates the amplitude of $I_{\mathrm{sAHP}}$ in cortical pyramidal cells.

We next considered the possibility that other members of the NCS protein family could act as calcium sensors for $I_{\mathrm{SAHP}}$. Hippocalcin shares considerable sequence homology with the NCS proteins neurocalcin $\delta$ and VILIP1-3, and previous studies have suggested that these proteins may form a functionally distinct subfamily of visinin-like proteins (Burgoyne, 2007; Braunewell and Klein-Szanto, 2009). Therefore, we next transfected neurocalcin $\delta$, a close homolog of hippocalcin (91\% amino acid identity), and examined its effect on $I_{\mathrm{sAHP}}$. As illustrated in Figure Figure 2. Neurocalcin $\delta$, but not VILIP-2, increases the amplitude and prolongs the duration of $I_{\text {sAHP. }} A_{1}, I_{\text {sAHP }}$ recorded in a pyramidal cell transfected with neurocalcin $\delta$ (green) and in a neighboring untransfected control pyramidal cell (black) in the same slice. Inset, Graph summarizing the effect of neurocalcin $\delta$ on the amplitude of $I_{\text {sAHP }}$ in 8 cell pairs. ${ }^{*} p=0.012 . A_{2}, A_{3}$, Graphs illustrating the effects of neurocalcin $\delta$ expression on the amplitude $\left(\boldsymbol{A}_{2}\right)$ and decay $\left(\boldsymbol{A}_{3}\right)$ of $I_{\text {sAHP }}$ for each cell pair. The half decay for only 7 cell pairs is depicted in $\boldsymbol{A}_{3}$ because it was not possible to estimate the half decay for $I_{\text {sAHP }}$ in one of the control cells. $\boldsymbol{A}_{3}$, Inset, Traces in $\boldsymbol{A}_{\mathbf{1}}$ scaled to illustrate the slower time course of $I_{\text {sAHP }}$ induced by neurocalcin $\delta . \boldsymbol{B}_{1}, I_{\text {sAHP }}$ recorded in a cortical pyramidal cell transfected with VILIP-2 (green) and a neighboring control untransfected cell (black). Inset, Graph summarizing the amplitude of $I_{\text {SAHP }}$ in control cells and in cells transfected with VILIP-2. $\boldsymbol{B}_{\mathbf{2}}, \boldsymbol{B}_{\mathbf{3}}$, Graphs illustrating the effects of VILIP-2 on the amplitude $\left(\boldsymbol{B}_{2}\right)$ and decay $\left(\boldsymbol{B}_{\mathbf{3}}\right)$ of $I_{\text {sAHP }}$ for each cell pair tested in this experiment. $N=5$ cell pairs tested. $p=0.49$.
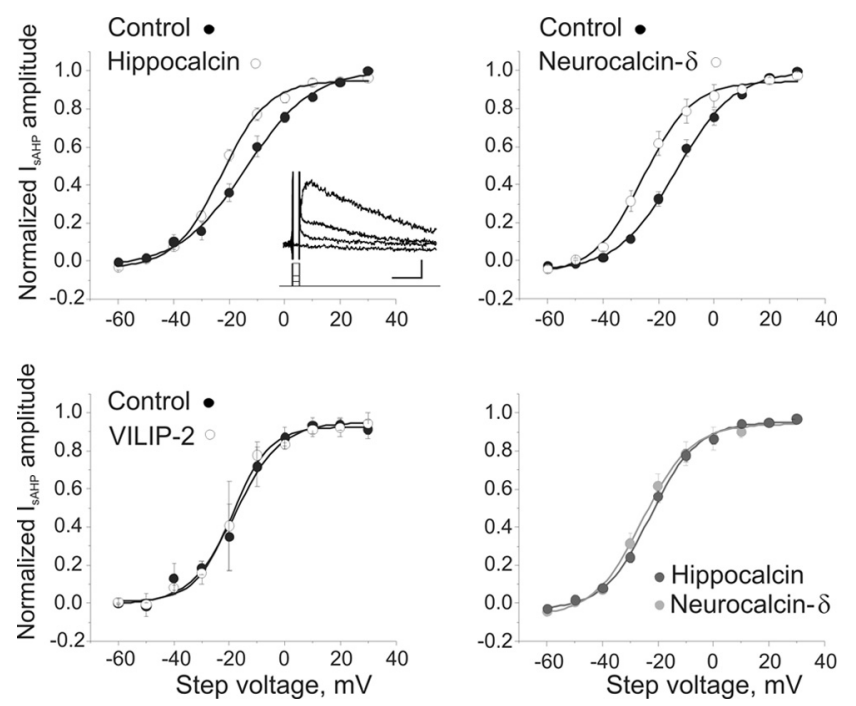

Figure 3. Effect of hippocalcin, neurocalcin $\delta$ and VILIP-2 on the apparent calcium sensitivity of $I_{\text {sAHP. }}$. Inset, Voltage steps to -60 to $+20 \mathrm{mV}$ were used to produce graded increases in calcium influx and hence graded activations of $I_{\text {sAHP }}$ (Gerlach et al., 2004). Calibration: 40 pA, $500 \mathrm{~ms}$. Expression of hippocalcin and neurocalcin $\delta$, but not of VILIP-2, resulted in an increase in the apparent calcium sensitivity of $I_{\text {sAHP. }}$. However, the apparent calcium sensitivity curves for cells transfected with hippocalcin or neurocalcin $\delta$ were superimposable (lower right). Hippocalcin, $n=15$ cell pairs; neurocalcin $\delta, n=6$ cell pairs, VILIP-2, $n=4$ cell pairs.

To test further the possible role of hippocalcin in mediating $I_{\text {sAHP }}$ in cortex, we transfected this NCS into pyramidal cells in cortical slices maintained in organotypic culture and assessed its effect on $I_{\text {sAHP }}$ using paired recordings from neighboring trans-
$2 A$, expression of neurocalcin $\delta$, like hippocalcin, again resulted in a large increase in $I_{\mathrm{sAHP}}$ amplitude (from $58 \pm 10$ to $98 \pm 10$ $\mathrm{pA}, n=8$ cell pairs, $p<0.01)$ and slowing of $I_{\mathrm{sAHP}}$ decay kinetics $(p<0.01)$. In contrast, transfection of VILIP-2, a more distant member of the hippocalcin subfamily of NCS proteins $(<70 \%$ amino acid identity), had no effect on either the amplitude or decay kinetics of $I_{\text {sAHP }}$ (Fig. $2 B$ ) (control: $63 \pm 13$ pA, VILIP-2 $59 \pm 5 \mathrm{pA}, n=5$ cell pairs, $p=0.79)$. Combined, these results indicate that $I_{\mathrm{sAHP}}$ can be regulated by at least two members of the visinin-like subfamily of NCS proteins.

Hippocalcin and neurocalcin $\delta$ are expressed in the cerebral cortex in a roughly overlapping pattern, suggesting coexpression at the cellular level (supplemental Fig. S4, available at www. jneurosci.org as supplemental material). Previous work has suggested that two or more NCS proteins exhibiting different calcium affinities may work in tandem to extend the dynamic range of calcium sensing (reviewed by Burgoyne, 2007). Therefore we considered the possibility that a hippocalcin and neurocalcin $\delta$ could sense different calcium concentrations to activate $I_{\text {sAHP. }}$. If that was the case, it could be expected that the hippocalcin- and neurocalcin $\delta$-enhanced $I_{\text {sAHP }}$ s should differ in their calcium sensitivity. To test this idea, we examined the apparent calcium sensitivity of $I_{\text {sAHP }}$ under control conditions and after transfection with hippocalcin or neurocalcin $\delta$. As illustrated in Figure 3, both hippocalcin and neurocalcin $\delta$, but not VILIP-2, shifted the apparent calcium sensitivity of $I_{\text {sAHP. }}$. However, the calcium-sensitivity curves for hippocalcin-enhanced and neurocalcin $\delta$-enhanced $I_{\text {sAHPs }}$ are superimposable (Fig. $3 B$, inset). These results do not support the idea that hippocalcin and neurocalcin $\delta$ sense different concentrations of calcium. 
Little is known at the present time about the molecular identity of the channels carrying $I_{\text {sAHP. }}$ This makes it difficult to unambiguously determine whether hippocalcin and neurocalcin $\delta$ facilitate the ion channels carrying the native current. As noted in the Introduction, one of the defining characteristics of $I_{\text {sAHP }}$ is its inhibition by neuromodulators acting through G-protein-coupled receptors signaling through $\mathrm{G} \alpha_{\mathrm{s}}$ or $\mathrm{G} \alpha_{\mathrm{q}-11}$. Previous studies have shown that carbachol inhibits $I_{\text {sAHP }}$ in pyramidal cells of the cerebral cortex by acting on muscarinic $\mathrm{M} 1 / \mathrm{M}_{3}$ receptors (Gulledge et al., 2009). At a biochemical level, these receptors activate $\mathrm{G} \alpha_{\mathrm{q}-11}$ and PLC $\beta$, leading to the breakdown of PtdIns $(4,5) \mathrm{P}_{2}$. Therefore we first tested whether carbachol indeed inhibited $I_{\mathrm{sAHP}}$ by activating $\mathrm{G} \alpha_{\mathrm{q}-11}$ and PLC $\beta$ in these cells. As illustrated in Figure $4 A$, the ability of carbachol to inhibit $I_{\text {sAHP }}$ was blocked by expression of the carboxy tail of PLC $\beta 1$ fused to GFP (PLC $\beta$-ct), a dominant-negative construct that blocks $\mathrm{G} \alpha_{\mathrm{q}-11}$ signaling in central and peripheral neurons (Kammermeier and Ikeda, 1999; Yan et al., 2009). In addition, the ability of carbachol to inhibit $I_{\text {sAHP }}$ was greatly reduced in animals in which PLC $\beta 1$, the predominant PLC $\beta$ isoform expressed in the cerebral cortex, had been deleted (Fig. 4A3) (Kim et al., 1997; Watanabe et al., 1998). These results indicated that carbachol inhibits $I_{\mathrm{sAHP}}$ in cortex through $\mathrm{G} \alpha_{\mathrm{q}-11}$ and, at least in part, PLC $\beta 1$. To examine the sensitivity of the NCS-enhanced $I_{\text {sAHP }}$ to inhibition by $\mathrm{G} \alpha \alpha_{\mathrm{q}-11}$ signaling, we transfected pyramidal cells with hippocalcin or neurocalcin $\delta$ and again examined the effects of carbachol. As illustrated in Figure $4 B$, administration of carbachol $(30 \mu \mathrm{M})$ inhibited $I_{\text {sAHP }}$ in these cells in a manner that was not statistically different from control ( $p=0.94)$, thus suggesting that the NCSenhanced $I_{\text {sAHP }}$ retains its ability to be inhibited by neuromodulators acting via $\mathrm{G} \alpha_{\mathrm{q}-11}$ and PLC $\beta$.

\section{Discussion}

The identification of hippocalcin as a calcium sensor for $I_{\text {sAHP }}$ in hippocampus, while making much-needed fresh inroads into our understanding of this current, raised a number of important mechanistic questions (Brown et al., 2007; Tzingounis et al., 2007). Most notably, the restricted expression of hippocalcin in the brain, and the only partial suppression of $I_{\text {sAHP }}$ in the hippocalcin knock-out mouse, questioned whether hippocalcin alone could account for the calcium sensitivity of $I_{\text {sAHP }}$ (Brown et al., 2007). In the current work, we used loss of function and overexpression approaches to show that hippocalcin regulates $I_{\text {sAHP }}$ in the cerebral cortex, and show that neurocalcin $\delta$, a closely related visinin-like NCS protein similarly expressed in this region, can also regulate $I_{\text {sAHP. }}$. These results solve inconsistencies surrounding the identification of hippocalcin as the calcium sensor for $I_{\mathrm{sAHP}}$ and point to a broader role for NCS proteins in the regulation of this current.

The original suspicion that hippocalcin may not be the sole calcium sensor for $I_{\text {sAHP }}$ was based not only on the presence of a residual $I_{\text {sAHP }}$ in the hippocalcin knock-out, but also on the observation that this residual $I_{\mathrm{SAHP}}$ is relatively resistant to inhibi- tion by norepinephrine acting through $\beta$-adrenergic receptors (Tzingounis et al., 2007). This led Brown et al. (2007) to suggest that $I_{\text {sAHP }}$ may be gated through two parallel branches exhibiting differential sensitivity to inhibition by norepinephrine. In the current work, we show that carbachol inhibits $I_{\text {sAHP }}$ in cortical pyramidal neurons by acting through $\mathrm{G} \alpha_{\mathrm{q}-11}$ and (at least in part) PLC $\beta 1$. Furthermore, we show that the native, the hippocalcinenhanced, and the neurocalcin $\delta$-enhanced $I_{\mathrm{sAHP}} S$ are all inhibited to a comparable extent by this signaling cascade. These results suggest that the $\mathrm{G} \alpha_{\mathrm{q}-11} / \mathrm{PLC} \beta$ signaling cascade does not distinguish between hippocalcin- and neurocalcin $\delta$-gated

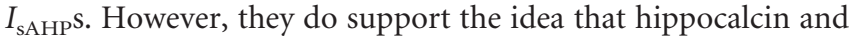
neurocalcin $\delta$ act on the native $I_{\text {sAHP. }}$.

The main finding of the current report is that at least two distinct NCS proteins can act as calcium sensors for $I_{\text {sAHP. }}$. But why should that be the case, especially since it seems likely that both these proteins are coexpressed in at least some cortical neurons? One possibility is suggested by the observation that NCS proteins with different calcium affinities can regulate a single molecular target to allow for an increase in the dynamic range of calcium sensing (reviewed by Burgoyne, 2007). In the current work, we find that while hippocalcin and neurocalcin $\delta$ both increase the apparent calcium sensitivity of $I_{\text {sAHP }}$, within the limits of this assay, the calcium sensitivities of these NCSenhanced $I_{\mathrm{sAHP}}$ s are indistinguishable. As such, these results are inconsistent with the idea that hippocalcin and neurocalcin $\delta$ sense different calcium concentrations when they regulate $I_{\text {sAHP }}$. Further studies are needed to clarify and understand this apparent redundancy.

The observation that the genetic deletion of hippocalcin results in a reduction in the amplitude of $I_{\text {sAHP }}$ has been interpreted to suggest that hippocalcin functions as calcium sensor for this current (Tzingounis et al., 2007). The results of the present experiments support this idea, while also extending such a role to neurocalcin $\delta$. Specifically, we now show that hippocalcin and 
neurocalcin $\delta$ increase not only the amplitude of $I_{\text {sAHP }}$ but also its calcium sensitivity. Since such an increase in calcium sensitivity would be predicted for the overexpression of a calcium sensor, these results support the idea that these NCS proteins sense calcium as part of the gating of $I_{\mathrm{sAHP}}$. Such an interpretation is consistent with previous studies showing that $I_{\mathrm{sAHP}}$ follows the time course of cytoplasmic calcium (Abel et al., 2004) and that hippocalcin shuttles from the cytoplasm to the membrane in response to rises in intracellular calcium, and does so with a time course compatible with a role in signaling $I_{\mathrm{sAHP}}$ (Markova et al., 2008). However, exactly how these visinin-like NCS proteins function in the context of gating $I_{\mathrm{sAHP}}$ is unclear. Clearly a more detailed understanding of the molecular mechanisms underlying $I_{\text {sAHP }}$ will be required to understand how these visinin-like NCS proteins regulate this enigmatic current.

\section{References}

Abel HJ, Lee JC, Callaway JC, Foehring RC (2004) Relationships between intracellular calcium and afterhyperpolarizations in neocortical pyramidal neurons. J Neurophysiol 91:324-335.

Bai J, Ramos RL, Ackman JB, Thomas AM, Lee RV, LoTurco JJ (2003) RNAi reveals doublecortin is required for radial migration in rat neocortex. Nat Neurosci 6:1277-1283.

Béique JC, Andrade R (2003) PSD-95 regulates synaptic transmission and plasticity in rat cerebral cortex. J Physiol 546:859-867.

Béique JC, Imad M, Mladenovic L, Gingrich JA, Andrade R (2007) Mechanism of the 5-hydroxytryptamine $2 \mathrm{~A}$ receptor-mediated facilitation of synaptic activity in prefrontal cortex. Proc Natl Acad Sci U S A 104:9870-9875.

Braunewell KH, Klein-Szanto AJ (2009) Visinin-like proteins (VSNLs): interaction partners and emerging functions in signal transduction of a subfamily of neuronal Ca2+-sensor proteins. Cell Tissue Res 335: 301-316.

Brown DA, Lancaster B, Shah MM (2007) Hippocalcin: a new solution to an old puzzle. Neuron 53:467-468.

Burgoyne RD (2007) Neuronal calcium sensor proteins: generating diversity in neuronal Ca2 + signalling. Nat Rev Neurosci 8:182-193.

Faber ES, Sah P (2003) Calcium-activated potassium channels: multiple contributions to neuronal function. Neuroscientist 9:181-194.

Gerlach AC, Maylie J, Adelman JP (2004) Activation kinetics of the slow afterhyperpolarization in hippocampal CA1 neurons. Pflugers Arch 448:187-196.

Gulledge AT, Bucci DJ, Zhang SS, Matsui M, Yeh HH (2009) M1 receptors mediate cholinergic modulation of excitability in neocortical pyramidal neurons. J Neurosci 29:9888-9902.

Higgs MH, Slee SJ, Spain WJ (2006) Diversity of gain modulation by noise in neocortical neurons: regulation by the slow afterhyperpolarization conductance. J Neurosci 26:8787-8799.

Kammermeier PJ, Ikeda SR (1999) Expression of RGS2 alters the coupling of metabotropic glutamate receptor 1a to M-type $\mathrm{K}+$ and N-type Ca2+ channels. Neuron 22:819-829.

Kim D, Jun KS, Lee SB, Kang NG, Min DS, Kim YH, Ryu SH, Suh PG, Shin HS
(1997) Phospholipase C isozymes selectively couple to specific neurotransmitter receptors. Nature 389:290-293.

Krause M, Offermanns S, Stocker M, Pedarzani P (2002) Functional specificity of $\mathrm{G} \alpha_{\mathrm{q}}$ and $\mathrm{G} \alpha_{11}$ in the cholinergic and glutamatergic modulation of potassium currents and excitability in hippocampal neurons. J Neurosci 22:666-673.

Lautermilch NJ, Few AP, Scheuer T, Catterall WA (2005) Modulation of CaV2.1 channels by the neuronal calcium-binding protein visinin-like protein-2. J Neurosci 25:7062-7070.

Madison DV, Nicoll RA (1982) Noradrenaline blocks accommodation of pyramidal cell discharge in the hippocampus. Nature 299:636-638.

Madison DV, Nicoll RA (1984) Control of the repetitive discharge of rat CA 1 pyramidal neurones in vitro. J Physiol 354:319-331.

Markova O, Fitzgerald D, Stepanyuk A, Dovgan A, Cherkas V, Tepikin A Burgoyne RD, Belan P (2008) Hippocalcin signaling via site-specific translocation in hippocampal neurons. Neurosci Lett 442:152-157.

Parsons BD, Schindler A, Evans DH, Foley E (2009) A direct phenotypic comparison of siRNA pools and multiple individual duplexes in a functional assay. PLoS One 4:e8471.

Paterlini M, Revilla V, Grant AL, Wisden W (2000) Expression of the neuronal calcium sensor protein family in the rat brain. Neuroscience 99:205-216.

Pedarzani P, Storm JF (1993) PKA mediates the effects of monoamine transmitters on the $\mathrm{K}+$ current underlying the slow spike frequency adaptation in hippocampal neurons. Neuron 11:1023-1035.

Saito T (2006) In vivo electroporation in the embryonic mouse central nervous system. Nat Protoc 1:1552-1558.

Saitoh S, Takamatsu K, Kobayashi M, Noguchi T (1994) Expression of hippocalcin in the developing rat brain. Brain Res Dev Brain Res 80:199-208.

Schwindt PC, Spain WJ, Foehring RC, Chubb MC, Crill WE (1988a) Slow conductances in neurons from cat sensorimotor cortex in vitro and their role in slow excitability changes. J Neurophysiol 59:450-467.

Schwindt PC, Spain WJ, Foehring RC, Stafstrom CE, Chubb MC, Crill WE (1988b) Multiple potassium conductances and their functions in neurons from cat sensorimotor cortex in vitro. J Neurophysiol 59:424-449.

Stoppini L, Buchs PA, Muller D (1991) A simple method for organotypic cultures of nervous tissue. J Neurosci Methods 37:173-182.

Tzingounis AV, Kobayashi M, Takamatsu K, Nicoll RA (2007) Hippocalcin gates the calcium activation of the slow afterhyperpolarization in hippocampal pyramidal cells. Neuron 53:487-493.

Villalobos C, Shakkottai VG, Chandy KG, Michelhaugh SK, Andrade R (2004) SKCa channels mediate the medium but not the slow calciumactivated afterhyperpolarization in cortical neurons. J Neurosci 24:3537-3542.

Villalobos C, Beique JC, Gingrich JA, Andrade R (2005) Serotonergic regulation of calcium-activated potassium currents in rodent prefrontal cortex. Eur J Neurosci 22:1120-1126.

Vogalis F, Storm JF, Lancaster B (2003) SK channels and the varieties of slow after-hyperpolarizations in neurons. Eur J Neurosci 18:3155-3166.

Watanabe M, Nakamura M, Sato K, Kano M, Simon MI, Inoue Y (1998) Patterns of expression for the mRNA corresponding to the four isoforms of phospholipase Cbeta in mouse brain. Eur J Neurosci 10:2016-2025.

Yan HD, Villalobos C, Andrade R (2009) TRPC channels mediate a muscarinic receptor-induced afterdepolarization in cerebral cortex. J Neurosci 29:10038-10046. 